\title{
BMJ Campylobacter epidemiology: Open a descriptive study reviewing 1 million cases in England and Wales between 1989 and 2011
}

To cite: Nichols GL, Richardson JF, Sheppard SK, et al. Campylobacter epidemiology: a descriptive study reviewing 1 million cases in England and Wales between 1989 and 2011. BMJ Open 2012;2:e001179. doi:10.1136/ bmjopen-2012-001179

- Prepublication history and additional materials for this paper are available online. To view these files please visit the journal online (http://dx. doi.org/10.1136/ bmjopen-2012-001179).

Received 20 March 2012 Accepted 22 May 2012

This final article is available for use under the terms of the Creative Commons Attribution Non-Commercial 2.0 Licence; see http://bmjopen.bmj.com

${ }^{1} \mathrm{HPA}$ Colindale, Health Protection Agency, London, UK

${ }^{2}$ University of Thessaly, Larissa, Greece

${ }^{3}$ University of East Anglia, Norwich, UK

${ }^{4}$ Department of Zoology, University of Oxford, Oxford, UK

${ }^{5}$ Institute of Life Science, College of Medicine, Swansea University, Swansea, UK ${ }^{6}$ Met Office, Exeter, Devon, UK

Correspondence to Professor Gordon L Nichols; gordon.nichols@hpa.org.uk

\section{ABSTRACT}

Objectives: To review Campylobacter cases in England and Wales over 2 decades and examine the main factors/mechanisms driving the changing epidemiology.

Design: A descriptive study of Campylobacter patients between 1989 and 2011. Cases over 3 years were linked anonymously to postcode, population density, deprivation indices and census data. Cases over 5 years were anonymously linked to local weather exposure estimates.

Setting: Patients were from general practice, hospital and environmental health investigations through primary diagnostic laboratories across England and Wales.

Participants: There were 1109406 cases.

Outcome measures: Description of changes in Campylobacter epidemiology over 23 years and how the main drivers may influence these.

Results: There was an increase in Campylobacter cases over the past 23 years, with the largest increase in people over 50 years. Changes in the underlying population have contributed to this, including the impacts of population increases after World War I, World War II and the 'baby boom' of the 1960s. A recent increase in risk or ascertainment within this population has caused an increase in cases in all age groups from 2004 to 2011. The seasonal increase in cases between weeks 18 (Early May) and 22 (Early June) was consistent across ages, years and regions and was most marked in children and in more rural regions. Campylobacter prevalence by week in each region correlated with temperature 2 weeks before. There were higher prevalences in areas with a low population density, low deprivation and lower percentage of people of ethnic origin. Data from sero-phage and multilocus sequence typing show a few common types and many uncommon types. Conclusions: The drivers/mechanisms influencing seasonality, age distribution, population density, socioeconomic and long-term differences are diverse and their relative contributions remain to be established. Surveillance and typing provide insights into Campylobacter epidemiology and sources of infection, providing a sound basis for targeted interventions.

\section{ARTICLE SUMMARY}

Article focus

- Campylobacter is the most common bacterial cause of diarrhoea, affecting about half a million people annually.

- Chicken is thought to be the most common source of infection and the most common vehicle for transmission while environmental sources are suspected to play an important role the seasonality.

- A few types are common and many types are rare.

Key messages

- Campylobacter is increasing in older people particularly men, and population structure is partly driving this increase.

- Antibiotic resistance has increased over recent years.

- There are lower rates of reporting in more densely populated areas and more deprived areas.

- The distribution of types suggests that immunity may be important.

Strengths and limitations of this study

- The study is large and captures patients from across the country, pulling together a good picture of the epidemiology of Campylobacter.

- The disease burden may be underestimated due to low reporting in deprived areas that may reflect poor access to healthcare or prior infection.

\section{INTRODUCTION}

Campylobacter is the most common bacterial cause of gastroenteritis in many developed countries and has been the subject of extensive research, with over 7500 peer-reviewed articles with Campylobacter in the title. It has been estimated that in the UK there were 
over half a million cases in the community in 2008-2009 and around 80000 general practice (GP) consultations. ${ }^{1}$ Chicken has been implicated as the source of infection in up to $80 \%$ of infections ${ }^{2}$ and as the risk factor associated with transmission in $41 \% .^{3}$ Actions to reduce the contamination of chickens in New Zealand have shown dramatic reductions in human cases. ${ }^{45}$ Despite this, the epidemiology of Campylobacter remains complicated and some of the features seem difficult to explain. These include the strong seasonal increase in cases, ${ }^{6}$ the higher rates of infection in men, ${ }^{6}$ the changing age distribution, ${ }^{7}$ the higher rates of infection and different risk factors in rural than in urban environments and the greater seasonality in rural than in urban environments. ${ }^{4-14}$ The study was set up to review the data reported to national surveillance on human Campylobacter infections in England and Wales over the past 22 years to provide an overview of trends and possible drivers, mechanisms and transmission routes.

\section{METHODS}

Campylobacter surveillance data reported from diagnostic laboratories in England and Wales from 1989 to 2011 were extracted from the Oracle (LabBase) database and analysed. Most of the analyses were for the period 1989 to 2009, but annual cases were extended to 2011 (2011 data provisional). All were laboratory-confirmed cases, most were symptomatic and included patients with extraintestinal infections. Standard antimicrobial testing methods, used in primary diagnostic laboratories, were predominantly disc diffusion methods. Where speciation was reported, it was conducted in diagnostic laboratories using conventional phenotypic methods. Cases were linked by postcode to lower-level super output area and medium-level super output area (MSOA), deprivation index, ethnic origin, population density and census data using data held on the Office for National Statistics website (http://www.statistics.gov.uk/cci/nugget.asp? $\mathrm{id}=6$ ). Postcodes of the diagnostic laboratories involved in primary isolation were used to link cases to local weather parameters held by the Met Office for 2005 to 2009. Temporal data were adjusted from day of year using a 7-day rolling mean, systematic adjustments for the reduced reporting over bank holidays and for longterm trend.

Phenotypic typing results were on human isolates, predominantly from samples taken in defined studies rather than during routine sampling. Data for the period of 1989 to 2009 included patients in a Campylobacter sentinel surveillance project, ${ }^{15}$ a case-control study ${ }^{3}$ and miscellaneous other sources. The majority of isolates were collected in a systematic way from all age groups, although the case-control study was confined to adults older than 18 years. Serotyping and phage typing were conducted at HPA Colindale using standard protocols, ${ }^{1617}$ and multilocus sequence typing (MLST) used recognised methods. ${ }^{18}$ Data from clinical samples are archived on the PubMLST database along with isolates from other sources, and figures are those entered in the database to September 2011.

\section{RESULTS}

\section{Clinical presentation}

Routine surveillance of 994791 Campylobacter patients between 1989 and 2009 showed that they were predominantly from gastrointestinal sites $(99.65 \%)$ and were associated with diarrhoea. There were 82 Campylobacter-related deaths $(0.008 \%)$. Overall, $242(0.25 \%)$ of isolates were from infections involving a sterile body site, including blood (1665), brain or cerebrospinal fluid (67), wounds (45), cardiac prostheses (15), peritoneum (6) and joints (3). A majority of Campylobacter fetus cases (61 of $72 ; 85 \%$ ) were invasive and $75 \%$ of $C$ fetus patients were older than 50 years compared with $44 \%$ of all Campylobacter isolates. Invasive infections were below $0.13 \%$ of all infections in people younger than 60 years $(1013 / 793874)$, but represented $0.37 \%$ of those between 60 and 79 years (539/145533) and $0.78 \%$ of infections in people older than 80 years (190/24252). Central nervous system cases were spread across the age groups in a broadly similar distribution to non-CNS cases when examined as a percentage of all cases (figure 1A), whereas fatal cases were more common in people older than 60 years than in other ages (figure 1B). There were 48 Campylobacter patients with Guillain-Barré or MillerFisher syndromes. Published studies indicate that the rate of Guillain-Barré syndrome in Campylobacter infections, when examined using a general practice research database, ${ }^{19}{ }^{20}$ was higher by a factor of 10-40 times in England, with an estimated 1.17 cases per 1000 per year. ${ }^{21}$ Three patients with Campylobacter had haemolytic uraemic syndrome, but without evidence that Campylobacter was the cause. Because reporting is passive and reliant on clinical details being recorded, there is likely to be under-reporting in both Guillain-Barré or MillerFisher syndromes and mortality data and differences in ascertainment of these between regions.

\section{Long-term changes}

There were 1109406 laboratory-confirmed cases reported to national surveillance between 1989 and 2011. Cases in 2011 were $45 \%$ above 2004 figures and $3 \%$ above 2010 figures (figure 1C). The cases rose from 33280 in 1989 to a peak of 58235 in 2000 before dropping to 44544 in 2004 and rising to a maximum 64582 in 2011 (2011 data provisional). There was a marked long-term increase in the percentage of cases in people older than 50 years (figure 1D), with a decline in the incidence in babies and children younger than 10 years from 2000 and a subsequent increase from 2006 to 2010. Figure $1 \mathrm{C}$ shows an increase in cases within all three age groups between 2004 and $2011(<10,36 \%$; 10-49, 25\%; $50+, 81 \%$ ), but for the period 1994 to 2000 , a $17 \%$ decrease in babies and children younger than 10 years, an increase in ages 10-49 years of $28 \%$ and an increase in people older than 50 years by $75 \%$. 


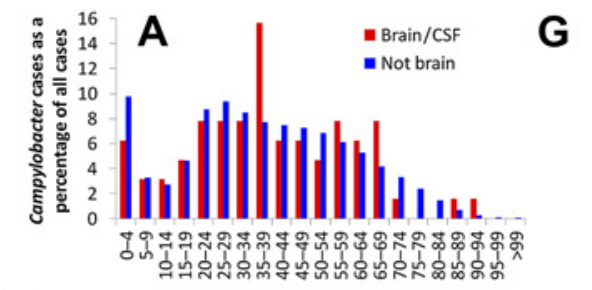

B
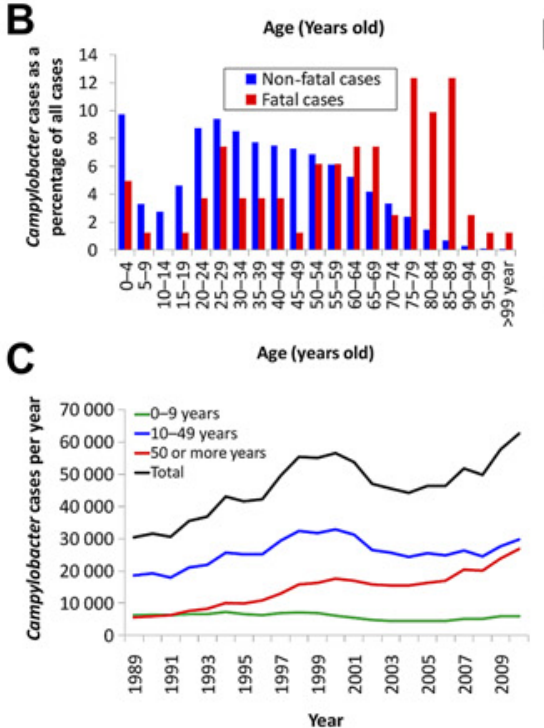

D

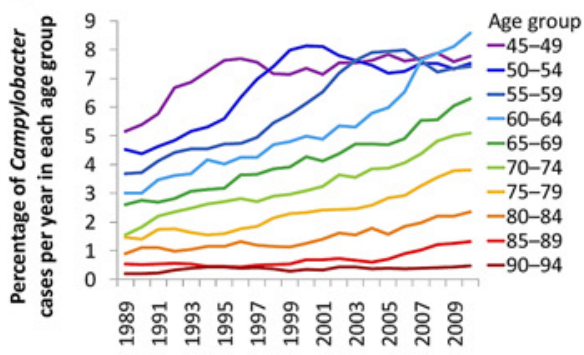

E
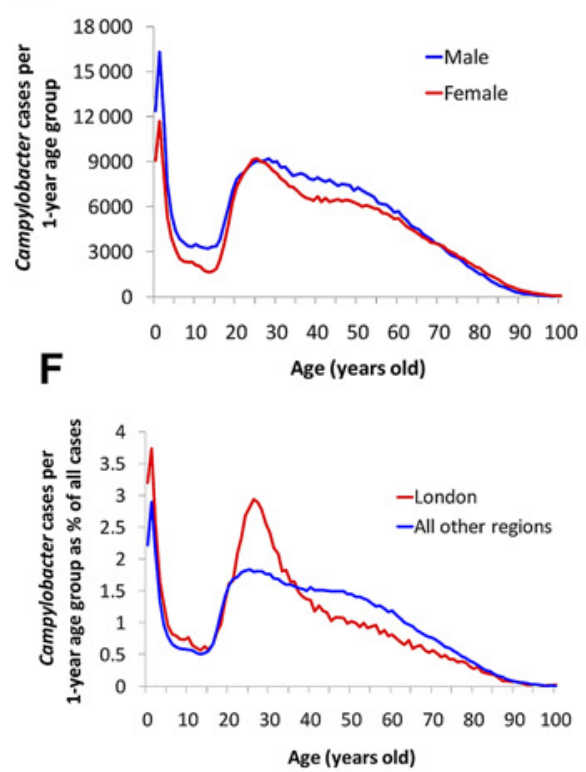

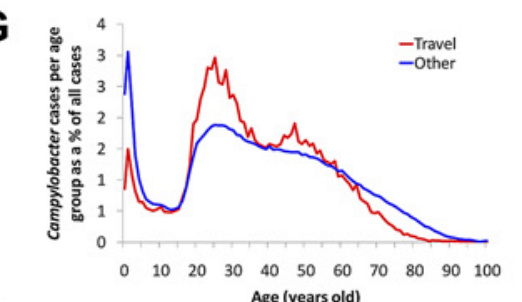

H
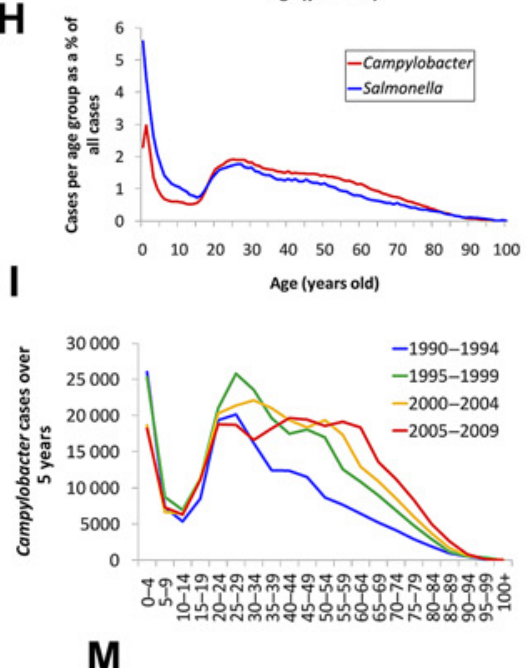

M

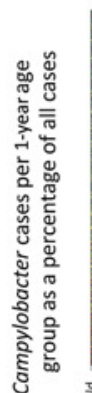

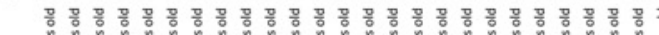

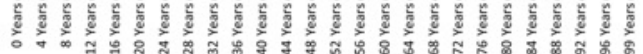
Male
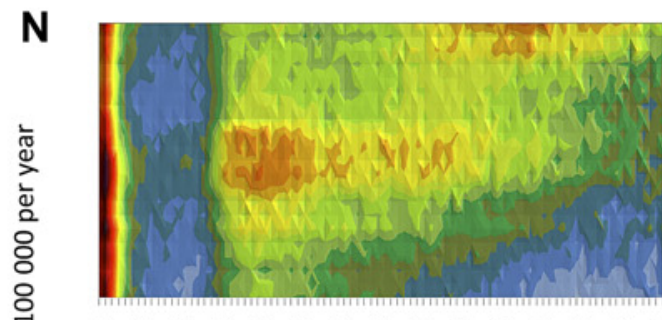

Year

2009

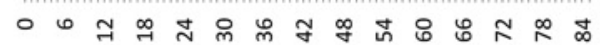
$2005 \quad \begin{gathered}\text { Cases per } \\ \end{gathered} \quad 100000$ per year

(2001 $2001 \quad 252-264$ $1997=240-252$ $1993 \quad$ 204-216 - 204-216 르 $180-192$ 180-192

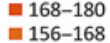
푸 $144-156$ 피 132-144 Female Age (years old)

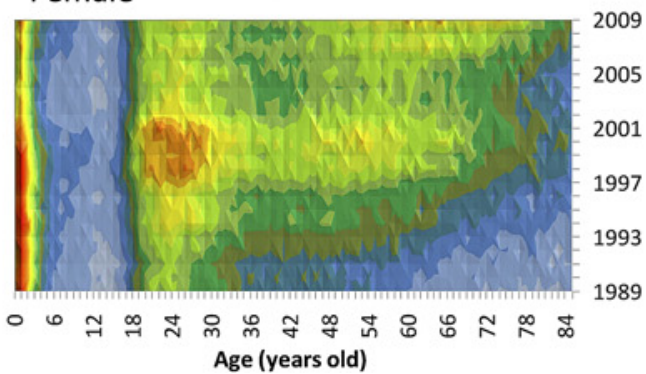
as a percentage of all cases, 1989-2009. (B) Campylobacter isolates from fatal and non-fatal cases in different age groups as 


\section{Age distribution}

There were $14 \%$ more reported Campylobacter cases in men than in women and a $1.14 \mathrm{M} / \mathrm{F}$ ratio across most ages (figure 1E). This was mirrored by the age-specific prevalence, which showed a $30 \%$ higher prevalence in men compared with women across most age groups (figure 1L). The age distribution varied geographically, with London having more infections in young adults and less in people older than 40 years (figure 1F). The age distribution of travel-related cases showed lower rates in children and people over 60 years and more cases in people between 20 and 35 years (figure 1G). The age distribution of cases between 1989 and 2010 differed significantly between Salmonella and Campylobacter, with a higher proportion of Salmonella cases in children and a higher proportion of Campylobacter cases in adults (figure $1 \mathrm{H}$ ). The age structure of cases has shifted over 20 years with more infection in older people in recent years (figure 1I). For example, comparison of Campylobacter data from 2008 (figure 1J) with 2008 population estimates (figure $1 \mathrm{~K}$ ) shows the impact of the age structure of the population on the prevalence in 2008 (figure 1L). The steady increase in the percentage of people older than 50 years (figure $1 \mathrm{M}$ ) partly reflects ageing of the underlying population. When examined as an age-specific prevalence, there has been a recent increase in infections in older people, particularly in men (figure $1 \mathrm{~N}$ ). There was also an increase in 20-32year-olds of both sexes around 2000 that was linked to the general increase in cases at this time. There was also a decline in the prevalence in children younger than 4 years from 2000 onwards. The seasonality of Campylobacter was much more marked in young children than in other ages (figure 2).

\section{Typing}

Campylobacter isolates from human cases between 1989 and 2009 (29 081/994 791; 2.9\%) could be differentiated into 64 serotypes (HS), 86 phage types (PT) and 949 combined HS/PT types. Isolates of Campylobacter jejuni contained 57 serotypes, 80 phage types and $866 \mathrm{HS} / \mathrm{PT}$ types and two thirds of serotypes of $C$ jejuni were represented in seven serotypes (table 1). Campylobacter coli contained 25 serotypes, 30 phage types and 102 HS/PT types, with five serotypes making up $84 \%$ of isolates (table 1). When the combined ST/PT of typable isolates were examined, then no type exceeded $9 \%$ of the total typed $C$ jejuni and $18 \%$ of typed $C$ coli strains. Among the combined HS/PT types, most isolates had few repre- sentatives (figure 3A), although the distribution differed when HS and PT were examined separately (figure $3 \mathrm{~B}$ ). Only 18013 of 26688 (67\%) C jejuni isolates and 1936 of $2393(81 \%) C$ coli isolates were typable. When combined as HS/PT type, this decreased to 16362 of 26688 (61\%) for $C$. jejuni, making phenotyping a poor tool for use in epidemiological investigation. Most of the HS/PT typing was undertaken between 2000 and 2004.

For the MLST data, all human cases reported on the PubMLST database were grouped by the seven sequenced genes (figure 3C-J), the ST and CC (figure 3K; table 1). Up to September 2011, there were 33 CCs and 757 STs among isolates from people with Campylobacter submitted to the PubMLST website (http:// pubmlst.org/campylobacter/). 94.8\% of C coli were of one type (ST-828 complex) and $34.2 \%$ of $C$ jejuni of two types (ST-21 complex and ST-257 complex). While most isolates clustered into one of the predominant CCs, the STs showed a distribution with a few common types and many types with low numbers of isolates (figure 3C-J). This may partly reflect the submission patterns for the PubMLST database, with 'rare' STs over-represented as a proportion of all isolates, although a similar distribution was found for the combined HS and PT types (figure 3A) where this was not an issue. The distribution of individual serotypes and phage types (figure 3B) mirrored that of the CCs (figure 3I).

\section{Antimicrobial resistance}

Over the period from 1989 to 2009, there was an increase in the percentage of Campylobacter isolates that were fully or intermediately resistant to ampicillin, ciprofloxacin, nalidixic acid, tetracycline and erythromycin (figure 4A). The percentage of strains that were resistant to ciprofloxacin was higher in people who had recently travelled abroad (1042/1601; 65\%) compared with those who had not $(2005 / 6530 ; 31 \%)$ and where travel status was not recorded (28646/ $90095 ; 32 \%)$. Isolates with high rates of resistance to ciprofloxacin were found in people who had travelled to India $(79 \%)$, Egypt $(79 \%)$, Spain $(78 \%)$ and Thailand $(80 \%)$.

\section{Weekends, bank holidays and other holidays}

The onset date was not reported for most Campylobacter infections; the specimen date was recorded in surveillance. Specimens with any single weekday ranged from $16.8 \%$ to $22.3 \%$ (average 19.0 ) of all cases, whereas cases were less common on Saturday $(2.5 \%-4.1 \%$; average

\footnotetext{
[Continued]

a percentage of all cases, 1989-2009. (C) Campylobacter cases per year from 1989 to 2011 by age (2011 data provisional). (D) Campylobacter cases per year 1989-2010 as a percentage of cases in different age groups over 45 years. (E) Campylobacter cases by age and sex, 1989-2009. (F) Campylobacter cases by age as a percentage of all cases for London and all other areas, 1898-2009. (G) Campylobacter cases in people who had recently returned from abroad and all other cases, 1989-2009. (H) Age distribution of Salmonella and Campylobacter. (I) Change in age distribution over four 5-year time periods. (J) Campylobacter age and sex distribution in 2008. (K) Population age and sex distribution in 2008. (L) Campylobacter cases per 100000 in 2008 by age and sex. (M) Campylobacter cases per 1-year age group as a percentage of all cases per year, 1989-2009. (N) Campylobacter prevalence per 100000 per year between 1989 and 2009 by age and sex. CSF, cerebrospinal fluid.
} 


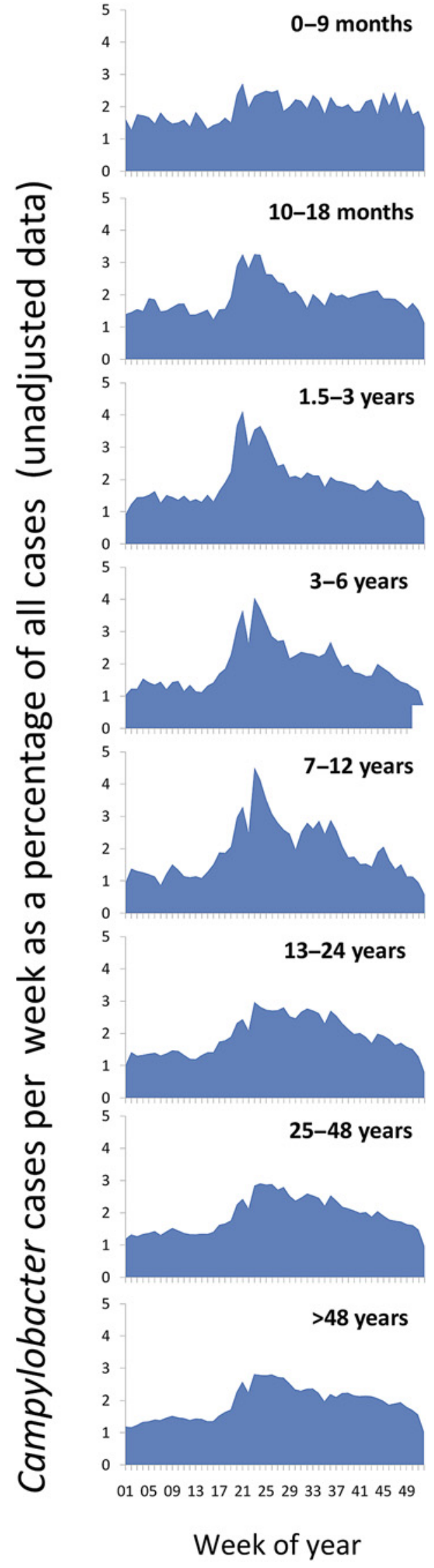

Figure 2 The weekly distribution of Campylobacter cases as a percentage of all cases over different age groups (unadjusted data).
3.2) and Sunday (1.4-2.1; average 1.7\%), presumably reflecting problems accessing medical services on weekends. This would include access to GP, hospital or diagnostic laboratory. The reporting of infections was on average $28 \%$ lower in the 7 days of bank holiday weeks, presumably reflecting difficulties in accessing medical services. There was extra reporting in the week following some bank holiday weeks, suggesting that some cases are merely delayed by the holiday (figure 4B). Other school holidays (eg, half term) may have some effect on case reporting but are more difficult to determine as they are arranged locally rather than nationally. There was no long-term trend in the bank holiday effect. August bank holidays are during a period when there is no school attendance, and school holidays are therefore less likely to contribute.

\section{Seasonality}

Cases were normalised to take account of day of week, bank holidays and long-term trend. This was applied to daily infection rates to create a well-defined time series that shows a regular seasonal increase in the late spring with some of the features of an annual epidemic (figure 4C), as previously observed, ${ }^{22}$ and is followed by a gradual decline over the rest of the year. The timing of the increase varies slightly between regions and between years. The increased rate of infection between weeks 18 (Early May) and 22 (Early June) is consistently seen every year in all regions but is more pronounced in young children (figure 4D,E), in some regions than others, and was less marked in London (figure $4 \mathrm{~F}$ ). Cases in this period represent $8 \%-12 \%$ of all annual cases and show a dramatic change over a few weeks in the exposure of people to infection, as short-term changes in ascertainment or susceptibility are unlikely. There was a relationship between Campylobacter prevalence and temperature that was partly a reflection of the higher seasonality in summer months when it is warmer (figure $4 \mathrm{~K}$ ) but could also represent a temperature-sensitive driver.

\section{Postcode prevalence}

The patient postcode is required to determine the local prevalence of Campylobacter and to produce maps of the MSOAs (figure 4G). However, in 2009, only $76 \%$ of patient surveillance records had an associated postcode, so the actual prevalence for some MSOAs was higher than this. The prevalence was higher in young children than in other ages (figure 1L). Overall prevalence in England and Wales for 2009 was 105 per 100000 per year. Campylobacter prevalence in some MSOAs was artificially lowered due to low postcode reporting. These maps show some areas with much higher rates of infection locally (320-1290 cases per 100000$)$ that were not all in areas of low population density. When MSOAs were examined, $76.5 \%$ of the areas had between 10 and 150 Campylobacter cases per 100000 per year, with $10.9 \%$ showing $<10$ per 100000 per year and $12.6 \%$ having between 150 and 560 per 100000 per year. 
Table 1 Serotypes (HS)*, phage types (PT)†, MLST sequence types (ST) and MLST clonal complexes (CC) of Campylobacter jejuni and Campylobacter coli in England and Wales, 2000-2009‡

\begin{tabular}{|c|c|c|c|c|c|c|c|c|c|}
\hline Serotype & & & & $\begin{array}{l}\text { Phage } \\
\text { type }\end{array}$ & & & & $\begin{array}{l}\text { Clonal } \\
\text { complex }\end{array}$ & \\
\hline HS & C. jejuni & coli & Total & PT & C. jejuni & C. coli & Total & $\mathrm{CC}$ & C. jejuni \\
\hline HS1 & 397 & & 397 & PT1 & 8647 & 201 & 8848 & CC 21 & 268 \\
\hline HS2 & 778 & 2 & 780 & PT2 & 2681 & 758 & 3439 & CC 22 & 22 \\
\hline HS3 & 155 & & 155 & PT3 & 4 & & 4 & CC 42 & 19 \\
\hline HS4 & 691 & & 691 & PT4 & 7 & & 7 & CC 45 & 92 \\
\hline HS5 & 592 & & 592 & PT5 & 1636 & 5 & 1641 & CC 48 & 79 \\
\hline HS6 & 466 & & 466 & PT6 & 538 & 7 & 545 & CC 49 & 16 \\
\hline HS7 & 22 & & 22 & $\mathrm{PT}$ & 8 & 139 & 147 & CC 52 & 24 \\
\hline HS8 & 398 & & 398 & PT8 & 545 & 11 & 556 & CC 61 & 51 \\
\hline HS9 & 357 & 33 & 390 & PT9 & 15 & & 15 & CC 206 & 51 \\
\hline HS10 & 22 & & 22 & PT10 & 63 & 2 & 65 & CC 257 & 117 \\
\hline HS11 & 203 & & 203 & PT11 & 13 & & 13 & CC 283 & 16 \\
\hline HS12 & 347 & 1 & 348 & PT13 & 12 & & 12 & CC 353 & 80 \\
\hline HS13 & 4008 & & 4008 & PT14 & 557 & 3 & 560 & CC 354 & 40 \\
\hline HS14 & 13 & 263 & 276 & PT15 & 34 & 1 & 35 & CC 362 & 2 \\
\hline HS15 & 19 & 1 & 20 & PT16 & 1 & & 1 & CC 403 & 19 \\
\hline HS16 & 161 & & 161 & PT17 & 63 & 5 & 68 & CC 433 & 3 \\
\hline HS17 & 2 & & 2 & PT18 & 63 & & 63 & CC 443 & 58 \\
\hline HS18 & 889 & 1 & 890 & PT19 & 473 & 1 & 474 & CC 446 & 11 \\
\hline HS19 & 386 & & 386 & PT20 & 336 & & 336 & CC 460 & 14 \\
\hline HS21 & 295 & & 295 & PT21 & 138 & & 138 & CC 464 & 9 \\
\hline HS22 & 31 & & 31 & PT22 & 4 & & 4 & CC 508 & 3 \\
\hline HS23 & 280 & & 280 & PT23 & 23 & & 23 & CC 573 & 12 \\
\hline HS24 & & 32 & 32 & PT24 & 14 & & 14 & CC 574 & 40 \\
\hline HS25 & & 4 & 4 & PT25 & 100 & 2 & 102 & CC 607 & 22 \\
\hline HS26 & & 9 & 9 & PT27 & 1 & & 1 & CC 658 & 30 \\
\hline HS27 & 239 & & 239 & PT28 & 14 & & 14 & CC 661 & 12 \\
\hline HS28 & 3 & 259 & 262 & PT29 & 9 & 3 & 12 & CC 677 & 1 \\
\hline HS29 & 1 & & 1 & PT30 & 3 & & 3 & CC 692 & 2 \\
\hline HS 30 & 33 & 17 & 50 & PT31 & 7 & & 7 & CC 702 & 2 \\
\hline HS 31 & 1315 & 2 & 1317 & PT32 & 9 & 9 & 18 & CC 828 & 1 \\
\hline HS 32 & 11 & & 11 & PT33 & 1726 & 4 & 1730 & CC 1034 & 9 \\
\hline HS33 & 28 & & 28 & PT34 & 1499 & & 1499 & CC 1287 & 1 \\
\hline HS 34 & 3 & 10 & 13 & PT35 & 630 & 1 & 631 & CC 1332 & 1 \\
\hline HS 35 & 69 & & 69 & PT36 & 573 & 2 & 575 & No CC & 166 \\
\hline HS 36 & 9 & & 9 & PT37 & 4 & & 4 & Total & 1293 \\
\hline HS37 & 892 & & 892 & PT38 & 150 & 1 & 151 & & \\
\hline HS 39 & & 9 & 9 & PT39 & 968 & 27 & 995 & & \\
\hline HS40 & 20 & & 20 & PT40 & 117 & 1 & 118 & & \\
\hline HS41 & 9 & & 9 & PT41 & 20 & & 20 & & \\
\hline HS42 & 57 & & 57 & PT42 & 6 & & 6 & & \\
\hline HS 43 & 33 & & 33 & PT43 & 32 & & 32 & & \\
\hline HS44 & 127 & & 127 & PT44 & 922 & 927 & 1849 & & \\
\hline HS45 & 10 & & 10 & PT45 & 34 & & 34 & & \\
\hline HS48 & 1 & 23 & 24 & PT46 & 4 & & 4 & & \\
\hline HS49 & 1 & 200 & 201 & PT47 & 2 & & 2 & & \\
\hline HS5O & 3528 & & 3528 & PT48 & 64 & & 64 & & \\
\hline HS51 & 2 & 41 & 43 & PT49 & 5 & & 5 & & \\
\hline HS52 & 50 & & 50 & PT50 & 15 & & 15 & & \\
\hline HS53 & 2 & & 2 & PT51 & 3 & & 3 & & \\
\hline HS55 & 70 & & 70 & PT52 & 10 & & 10 & & \\
\hline HS56 & 7 & 699 & 706 & PT53 & 75 & & 75 & & \\
\hline HS57 & 42 & & 42 & PT54 & 127 & & 127 & & \\
\hline HS58 & 2 & & 2 & PT55 & 4 & & 4 & & \\
\hline HS59 & 4 & 32 & 36 & PT56 & 18 & & 18 & & \\
\hline HS60 & 413 & & 413 & PT57 & 7 & & 7 & & \\
\hline HS61 & 1 & 82 & 83 & PT58 & 19 & & 19 & & \\
\hline HS62 & 10 & & 10 & PT59 & 18 & & 18 & & \\
\hline HS63 & 217 & 1 & 218 & PT60 & 13 & & 13 & & \\
\hline HS66 & & 215 & 215 & PT61 & 11 & & 11 & & \\
\hline HS67 & 117 & & 117 & PT62 & 170 & & 170 & & \\
\hline HS68 & 101 & & 101 & PT63 & 139 & 2 & 141 & & \\
\hline HS69 & 74 & & 74 & PT64 & 87 & 2 & 89 & & \\
\hline UT & 8675 & 457 & 9132 & PT65 & 102 & 1 & 103 & & \\
\hline Total & 26688 & 2393 & 29081 & PT66 & 16 & 3 & 19 & & \\
\hline & & & & PT67 & 201 & 1 & 202 & & \\
\hline & & & & PT68 & 6 & & 6 & & \\
\hline & & & & PT69 & 11 & 1 & 12 & & \\
\hline & & & & PT70 & 8 & 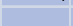 & 8 & & \\
\hline & & & & PT71 & 20 & & 20 & & \\
\hline & & & & PT72 & 7 & & 7 & & \\
\hline & & & & P 773 & 66 & 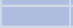 & 66 & & \\
\hline & & & & PT74 & 18 & & 18 & & \\
\hline & & & & PT75 & 61 & & 61 & & \\
\hline & & & & PT76 & 12 & & 12 & & \\
\hline & & & & PT77 & 43 & 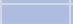 & 43 & & \\
\hline & & & & P778 & 20 & 1 & 21 & & \\
\hline & & & & PT79 & 9 & 3 & 12 & & \\
\hline & & & & PT80 & 147 & & 147 & & \\
\hline & & & & PT81 & 1 & & 1 & & \\
\hline & & & & PT82 & 47 & 2 & 49 & & \\
\hline & & & & PT83 & 5 & & 5 & & \\
\hline & & & & PT84 & 7 & & 7 & & \\
\hline & & & & PT85 & 4 & & 4 & & \\
\hline & & & & PT86 & 1 & & 1 & & \\
\hline & & & & PTRDNC & 1052 & 53 & 1105 & & \\
\hline & & & & PTUT & 1334 & 214 & 1548 & & \\
\hline & & & & Total & 26688 & 2393 & 29081 & & \\
\hline
\end{tabular}

While isolates from some HS/PT types were confined to $C$ jejuni or $C$ coli, 17 types occurred in both, although in most there was a predominance of one species. The exception was HS9 PT44, which was roughly equal in numbers. Other types included HS12 PT44, HS14 PT1, HS14 PT44, HS18 PT2, HS2 PT44, HS30 PT1, HS31 PT39, HS34 PT1, HS49 PT2, HS51 PT2, HS56 PT1, HS56 PT2, HS56 PT44, HS61 PT1, HS9 PT1, HS9 PT2. It is notable that in isolates showing the same phage and serotype pattern between $C$ jejuni and $C$ coli, the HS56, HS9, PT1, PT2 and PT44 phenotypes were prominent.

*Two thirds of serotypes of $C$ jejuni were represented in seven serotypes (HS13, 22\%; HS50, 20\%; HS31, 7\%; HS37, 5\%; HS18, 5\%; HS2 and HS4, $4 \%$ ).

† $84 \%$ of $C$ coli were in five serotypes (HS56, 36\%; HS14, 14\%; HS28, 13\%; HS66, $11 \%, \mathrm{HS} 49,10 \%$ ).

$\neq$ Campylobacter typing results are from $C$ jejuni and $C$ coli, but other species identified at HPA Colindale were: Arcobacter butzleri (50), $A$ cryaerophilus (4), A species (1), Campylobacter fetus (123), C hyointestinalis (2), C lari (8), C upsaliensis (50), Helicobacter canadensis (2), H cinerea (1), $H$ pullorum (2). 


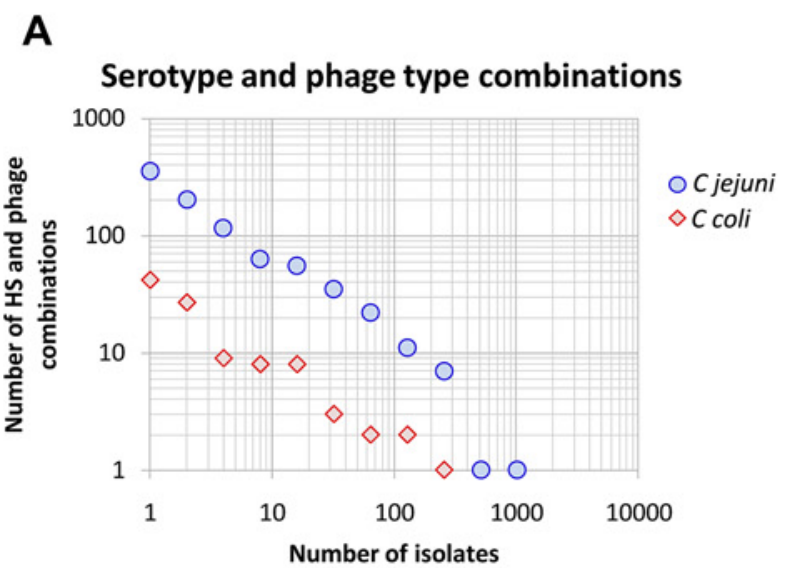

\section{B Individual sero and phage types of Campylobacter}
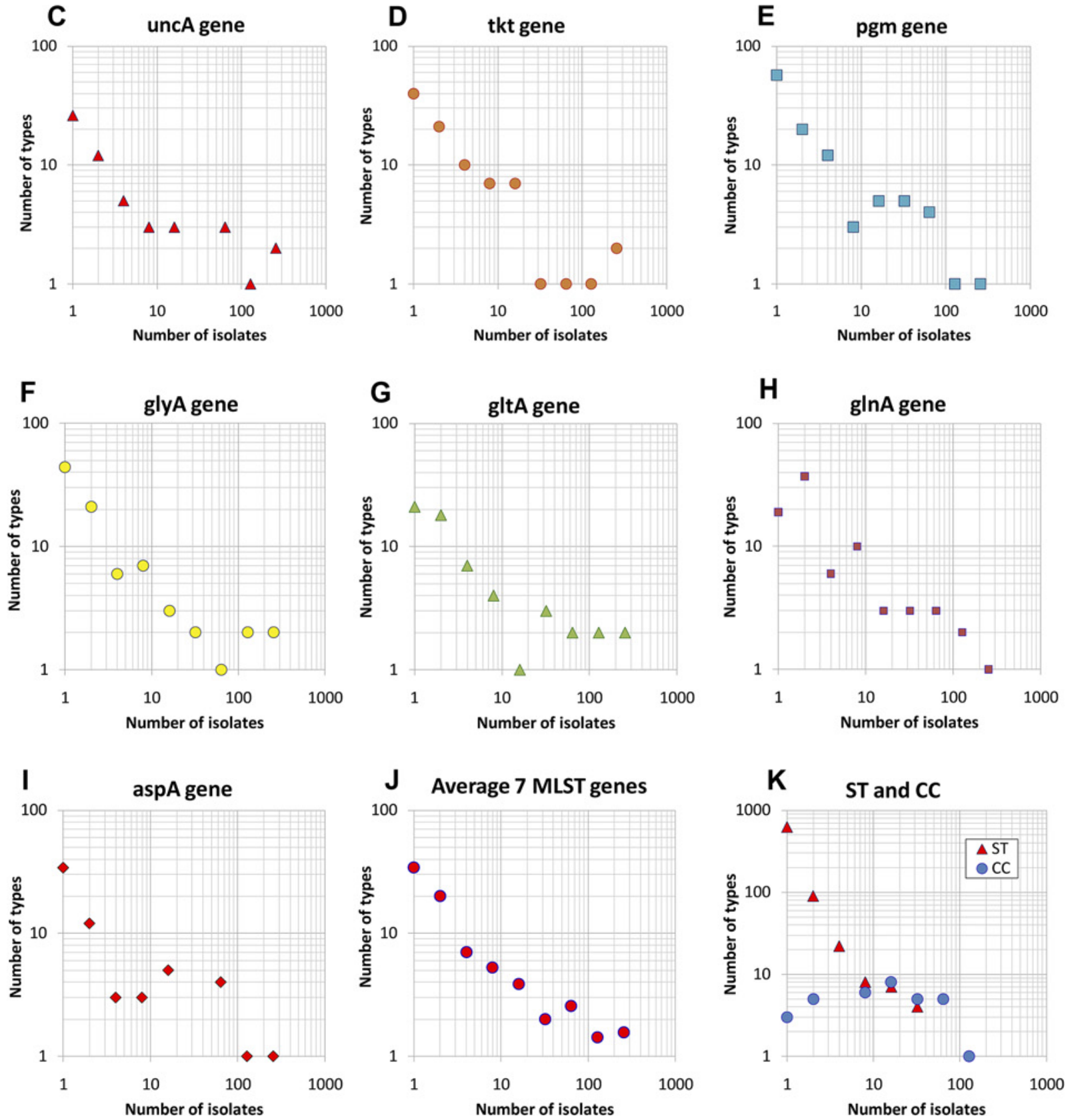

Figure 3 Typing. Typing data on cases of Campylobacter from England and Wales, 1989-2009. Data in the HPA data set (29081 isolates) includes the number of Campylobacter jejuni and Campylobacter coli combined serotype (HS) and phage type (PT) combinations (HS/PT) against the number of isolates in each type (A) the separate HS and PT types for $C$ jejuni and $C$ coli (B). 
Population density, urban/rural distribution, ethnicity and deprivation

For years 2007 to 2009 data, population density and deprivation were derived from the postcode data. Cases of Campylobacter per 100000 population were higher in areas of low population density (rural) compared with areas of high population density (urban settings) (figure $4 \mathrm{I})$. Less postcode reporting in areas of high population density or deprivation could introduce some bias; however, subset analysis of areas with over $90 \%$ postcode reporting still showed higher prevalence in areas of lower population density. The reason for the urban/ rural difference remains unclear but could reflect proximity to ruminants and other farmed animals or differences in access to healthcare. There was an inverse relationship between Campylobacter prevalence and the Oxford Index of Multiple Deprivation. People with Campylobacter from deprived areas were less frequently reported to surveillance than in less deprived areas (figure 4J). The reason could reflect different diets, prior exposure conferring some resistance or reduced access to healthcare. The prevalence of Campylobacter in communities where more than $95 \%$ of the population was 'white British' was greater than those where the percentage was $<50 \%$, possibly due to poorer access to healthcare, greater susceptibility or increased exposure.

\section{Overseas travel}

Overseas travel to both EU and non-EU countries was associated with almost a fifth of all Campylobacter infections in data from enhanced surveillance. Spain, the country most visited, remains the country with the largest source of travel-related cases. Routine surveillance of travelrelated cases shows poor and inconsistent ascertainment. Less is known about the risk factors responsible for travelrelated Campylobacter than from indigenous infections and the risks may vary between countries visited.

\section{Chicken production}

The long-term change in Campylobacter cases in England and Wales was compared with poultry produced in the UK after removing exports and including imports (figure $4 \mathrm{H}$ ). Data were from the Defra website (http:// www.defra.gov.uk/statistics/foodfarm/food/slaughter/). Chicken production was used as a surrogate for chicken consumption and showed that over the 23-year period the relationship was not linear, implying that Campylobacter prevalence is not directly related to the amount of chicken consumed.

\section{DISCUSSION}

The reasons for large long-term changes in Campylobacter cases, the spring increase, the increase in older people, the higher cases in rural communities and more cases in less deprived people could be related to features of diagnosis and reporting (commonly referred to as ascertainment) or of disease within the population as a result of increased exposure or susceptibility (here referred to as risk). The increase in cases in all three age groups between 2004 and 2009 can be compared with the period 1994 to 2000 where there was a decrease in cases in babies and children younger than 10 years, the increase in cases in people aged 10-49 years and the large increase in people older than 50 (figure 1C). This suggests that the drivers are complex and may include changes in attribution and risk. It has been suggested that some of the cases in children may be less likely to attend a physician and have a specimen taken as a result of the triaging associated with NHS Direct, ${ }^{7}$ although the people responding to NHS Direct are a small proportion of those with diarrhoea. ${ }^{1}$

In order to examine the impacts of various factors on the long-term change, seasonal increase, increase in people more than 50 years old, the urban/rural split and the socioeconomic factors, a table was drawn up (table 2). The increase in Campylobacter in patients older than 50 years between 2004 and 2010 is dramatic and may be linked to proton pump inhibitor use. These drugs may increase people's susceptibility to Campylobacter, 3 8 23-25 and the older population group are more likely to be taking these drugs than the younger ones. The underlying demographic drive in figure $1 \mathrm{M}$, where the increased birth rate after World War I and World War II and the 1960s baby boom is represented by diagonal lines, shows the impact of population size on Campylobacter cases over the years. This demographic drive is likely to contribute to the age distribution of cases, as the number of older people in the population is increasing but may also influence year-on-year changes. The economic downturn, which began in 2008, may have changed people's eating habits and exposed people to foods that are more commonly contaminated with Campylobacter. Alternatively, the chicken products within retail shops may have become more contaminated or there could be increased consumption of more contaminated products like chicken liver. There may also be effects resulting from a reduction in GP consultations for infectious intestinal disease. ${ }^{26}$ The increase in cases since 2004 seems to be across all ages. People may be eating outside the home more than they were 20 years ago and travel abroad is more common. Some of the discontinuities in laboratory reporting may have an impact on long-term trends as the data show particular periods where reporting was incomplete. However, there is also evidence from laboratories that have consistently reported over the 20-year surveillance period that the

[Continued]

The PubMLST database (1394 isolates) shows the number of types from human cases against the number of patient isolates. The figures represent individual sequenced genes for uncA (C), tkt (D), pgm (E), glyA (F), gltA (G), glnA (H) and aspA (I), with an average of the seven genes $(\mathrm{J})$ and the individual ST and CC (K). 

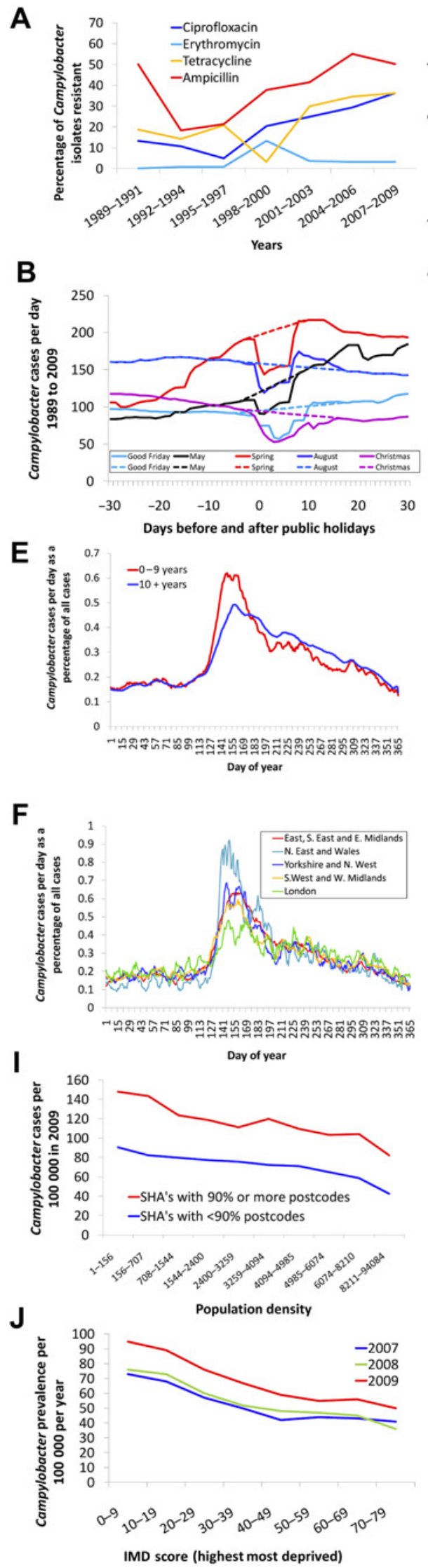

C

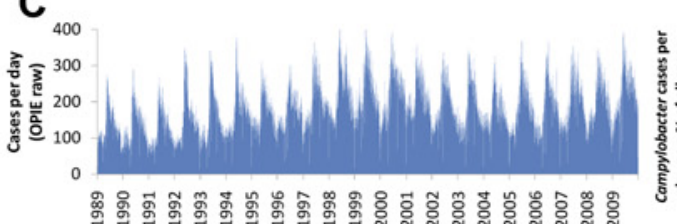

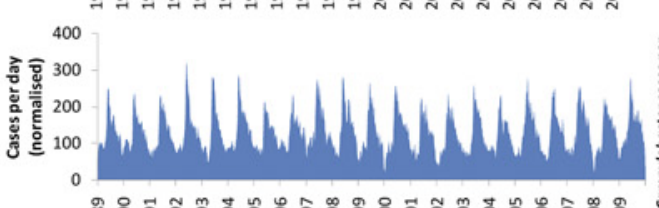

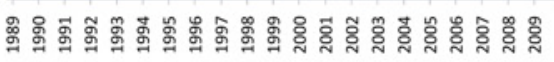
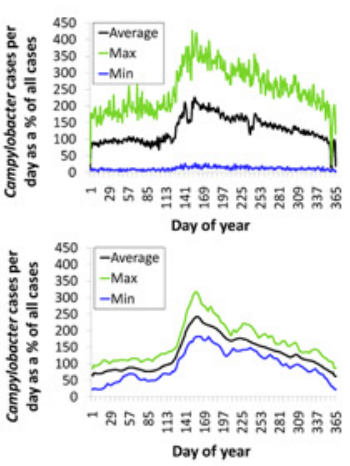

D

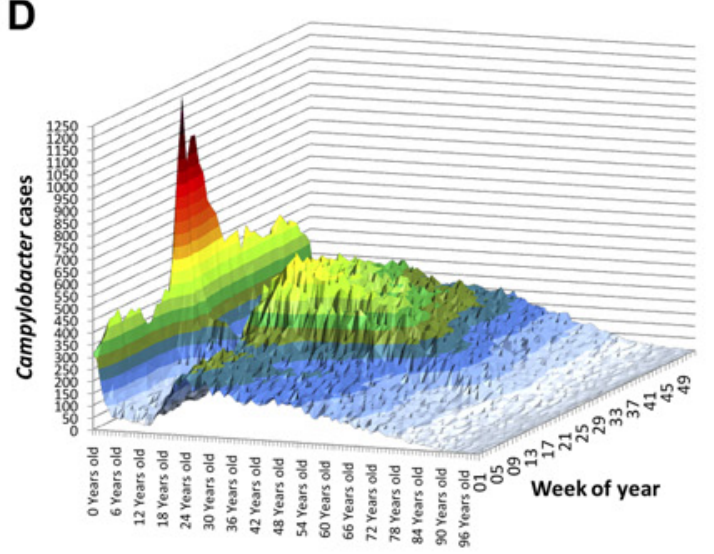

- 1200-1250 -1150-1200

- 1100-1150

-1050-1100

-1000-1050

- 950-1000

- $900-950$

- 850-900

ㅁ 800-850

ㅁ $750-800$

- $700-750$

= 650-700

두 600-650

프 $550-600$

500-550

450-500

-400-450

피 $350-400$

- $300-350$

= 250-300

- 200-250

ㅁ 150-200

Age
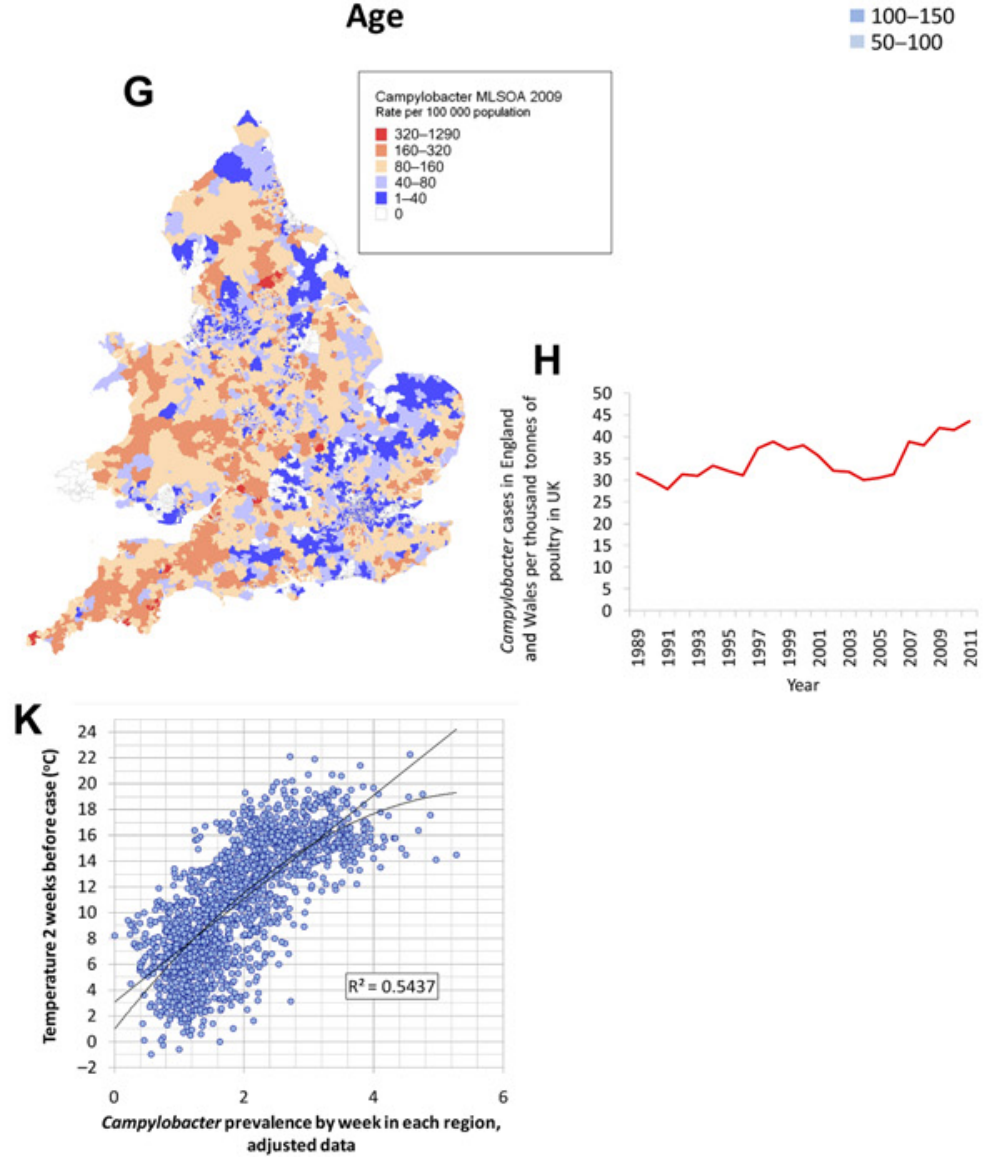

Figure 4 Resistance, spatial, social and temporal distribution. (A) Resistance of Campylobacter isolates to antibiotics between 1989 and 2009. (B) Campylobacter cases per day before and after bank holidays in England and Wales, 1989-2009. The dotted line represents an estimate of the cases that would have occurred if there had not been a bank holiday. (C) Time series of 
rates of long-term change were similar to those for all laboratories. There could have been systematic change in recent years in the efficiency of isolation, either through reduced specimen delay or improved culture media or culture conditions (eg, atmosphere). In a longitudinal study of infectious intestinal disease, detection of Campylobacter was better with culture and/or PCR than with culture alone. ${ }^{1}$ In addition, there was better isolation by culture alone in community cases than in those presenting to GPs when compared with culture and PCR, possibly reflecting greater delay in GP samples being sent for culture compared with community cases (Tam, personal communication).

\section{Seasonality}

The late spring increase in cases, particularly in children where the increase over a few weeks can be fourfold in some regions, has remained an enigma for many years $^{62728}$ and implies a seasonal driver that is probably indirect and related to environmental and climatic conditions. ${ }^{6}$ The seasonality differs by region, by year and by latitude and longitude, suggesting that weather combined with the farming environment is important. Possible drivers include increased contamination of chicken $^{29-32}$ and transmission by flies ${ }^{22} 33$ (table 2). Published evidence indicates that children in rural areas are more likely to be infected with ruminant strains, ${ }^{10}$ presumably from direct or indirect contamination from the environment. Data on seasonal distribution (figure 4C), and from typing data (table 1), make it unlikely that a single common source is the driver and imply contamination from multiple sources. There remains a need to tease out the contributions from possible drivers. There is a similar seasonality in Campylobacter contamination of chicken flocks ${ }^{34}$ and human disease ${ }^{35}$ where environmental drivers may be important. ${ }^{6} 2836$ While the seasonality of human infections correlates with climatic variables ${ }^{28} 36$ and chicken contamination, ${ }^{37} 38$ the rise in human cases can precede that in chickens, ${ }^{39}$ consistent with a common factor causing the increase in both. It has been suggested that flies might be the route by which Campylobacter enter chicken flocks, ${ }^{40-42}$ and some modelling of chicken data supports this hypothesis. ${ }^{43}$ In addition, transmission of Campylobacter to humans by flies has been hypothesised as a way of explaining the characteristic seasonality of human Campylobacter infections, ${ }^{22} 3344$ although testing this may prove difficult. ${ }^{45}$ The seasonal distribution of
Campylobacter in different countries may be related to their differing weather patterns. ${ }^{28}$ While water-based hypotheses are attractive because Campylobacter is common in natural waters, the general absence of geographically located point-source outbreaks would be inconsistent with this transmission route contributing to seasonality. Travel-related infections are seasonal but do not coincide with the spring increase.

\section{Typing}

The typing of Campylobacter isolates has proved useful in outbreak investigation using HS/PT typing and MLST typing and also in attributing strains to particular host sources using MLST typing. ${ }^{46} 47$ The distribution of different HS/PT types, with a few common types and a long tail of rare ones, is similar to that previously reported for Campylobacter using MLST typing, but the ability to group into clonal complexes makes MLST a more practical scheme for attribution. These data provide some indication of the potential diversity of phenotypes that reflect the labile genetic structure of this organism.

Data on the individual seven MLST alleles and on the HS/PT typing provide a way of looking at the genetic diversity of Campylobacter isolates from human infections. The frequency of different types from PubMLST may be influenced by inconsistencies in data submission and by bias towards rarer types so more unusual types appear than they would in a natural population. For the Sentinel Surveillance data, the isolates were collected in a more systematic way and are therefore more representative. The observed distribution for individual MLST alleles, for ST types and for combined HS/PT types might suggest that the most common types are perhaps those most easily able to propagate themselves within human or animal hosts. However, there is little evidence supporting this conjecture. The CCs have a clear utility in gathering up the organisms that are genetically similar, with the result that there is a different distribution with many CCs having more isolates within them, making source attribution more straightforward. The CCs shows a rough similarity, in comparing the number of isolates of different type, to the individual HS types and to the individual PT types.

\section{Antibiotics}

The increasing resistance of isolates to antibiotics is partly due to an increase in quinolone resistance in

[Continued]

Campylobacter by day of year 1989-2009 showing unmodified data (OPIE raw), data adjusted for day of week (OPIE), for bank holidays (adjusted) and also adjusted for long-term trend (normalised). (D) Campylobacter cases by age and week of year. (E) Seasonal distribution of cases over and under 10 years of age (normalised data). (F) Regional differences in seasonal distribution (normalised data). ( $\mathrm{G}$ and H) Campylobacter prevalence per 100000 for 2009 based on the medium-level lower super output areas (MLSOA) (H) Campylobacter cases in England and Wales per thousand tonnes of poultry in the UK. (I) Campylobacter cases per 100000 in 2009 by population density and completeness of postcode reporting. (J) Campylobacter prevalence per 100000 per year and the Index of Multiple Deprivation (IMD) score. Differences between 2007 and 2009 reflect improving postcode reporting as cases cannot be included in the figures without a postcode. (K) Campylobacter prevalence by week in each region against the local temperature 2 weeks before the case specimen date (2005-2009). 
Table 2 The main hypothesised drivers/mechanisms/transmission routes for changes in Campylobacter

\begin{tabular}{|c|c|c|c|c|c|}
\hline \multirow[b]{2}{*}{ Hypothesised contributing factor } & \multicolumn{5}{|c|}{ Estimated likelihood of causing } \\
\hline & $\begin{array}{l}\text { Long-term } \\
\text { change }\end{array}$ & $\begin{array}{l}\text { Seasonal } \\
\text { spring } \\
\text { increase }\end{array}$ & $\begin{array}{l}\text { Increase in } \\
\text { adults older } \\
\text { than } 50 \text { years }\end{array}$ & $\begin{array}{l}\text { More rural } \\
\text { than urban } \\
\text { cases }\end{array}$ & $\begin{array}{l}\text { More cases } \\
\text { in the more } \\
\text { affluent }\end{array}$ \\
\hline \multicolumn{6}{|l|}{ Surveillance ascertainment } \\
\hline Impacts of NHS Direct & Medium & Low & Low & Low & Low \\
\hline National reporting & Medium & Low & Low & Low & Low \\
\hline Changes in the surveillance system & Low & Low & Low & Low & Medium \\
\hline Changes in Campylobacter culture media & Medium & Low & Low & Low & Low \\
\hline Laboratory testing policy & Medium & Low & Low & Low & Low \\
\hline $\begin{array}{l}\text { New laws requiring laboratory notification } \\
\text { of Campylobacter* }\end{array}$ & Low & Low & Low & Low & Low \\
\hline \multicolumn{6}{|l|}{ Susceptibility } \\
\hline Increased proton pump inhibitor use & High & Low & High & Low & Low \\
\hline Immunity through prior exposure or infection & Low & Low & Low & Low & Medium \\
\hline Physiological differences between gender & Low & Low & Low & Low & Low \\
\hline \multicolumn{6}{|l|}{ Exposure } \\
\hline Increased contamination of chicken & High & Medium & Low & Low & Low \\
\hline Increased consumption of chicken & Medium & Low & Low & Low & Medium \\
\hline $\begin{array}{l}\text { Increased systemic Campylobacter } \\
\text { infection in chicken }\end{array}$ & High & Medium & Low & Low & Low \\
\hline Sourcing chicken from different areas & Medium & Low & Low & Low & Medium \\
\hline Increase in non-chicken-related sources & Low & Low & Low & Medium & Low \\
\hline Transmission from cattle to chickens by flies & Low & High & Low & Low & Low \\
\hline $\begin{array}{l}\text { Transmission from faeces or raw meat } \\
\text { to ready-to-eat food by flies }\end{array}$ & Low & High & Low & High & Low \\
\hline Biosecurity interventions for Salmonella control & Medium & Low & Low & Low & Low \\
\hline Country walks & Medium & Medium & Medium & High & Medium \\
\hline Contamination from agricultural animals & Medium & Medium & Low & High & Medium \\
\hline Contamination from pets & Low & Medium & Low & Medium & Low \\
\hline Contamination from wild birds & Low & Medium & Low & Low & Low \\
\hline Food preparation involving raw meats & Medium & Low & Low & Medium & Low \\
\hline Educational farm visits & Medium & Medium & Low & Medium & Medium \\
\hline Barbecued or grilled meat & Medium & High & Medium & Low & Low \\
\hline Private or untreated water supplies & Low & Medium & Low & Medium & Medium \\
\hline Mains drinking water & Low & Low & Low & Low & Low \\
\hline Surface water/sewage exposure & Medium & Medium & Low & Medium & Low \\
\hline \multicolumn{6}{|l|}{ Social factors } \\
\hline Population ageing/demographic change & High & Low & High & Medium & Low \\
\hline The economic situation & Medium & Low & Low & Low & Medium \\
\hline Socioeconomic status & Medium & Low & Low & Medium & High \\
\hline Changes in Campylobacter in other countries & Medium & Medium & Low & Low & Low \\
\hline Kitchen behaviour & Low & Low & Low & Low & Low \\
\hline GP access & High & Low & Low & High & High \\
\hline Two weekly waste bin collections & Low & Low & Low & Low & Low \\
\hline Travel abroad & Medium & Low & High & Low & High \\
\hline Eating out & Medium & Low & Medium & Low & Medium \\
\hline \multicolumn{6}{|l|}{ Environmental factors } \\
\hline Temperature & Low & Medium & Low & Low & Low \\
\hline Rainfall & Low & Low & Low & Low & Low \\
\hline Latitude/longitude & Low & Medium & Low & Medium & Low \\
\hline
\end{tabular}

people returning from travel abroad and partly increased resistance to other antibiotics in isolates from all areas. The rise in resistance to erythromycin has been less dramatic and does not show an association with foreign travel. It is therefore probably related to domestic human use of this drug.
Poultry

This study suggests that long-term changes in Campylobacter infection in humans do not correlate well with poultry production. This suggests that the degree of contamination may be more important than the total poultry weight produced. Most human infections are 
caused by $C$ jejuni and $C$ coli. Large studies have indicated that the Campylobacter isolates causing human infection contain a large diversity of types. Attribution studies indicate that strains that are commonly found in chickens are found in a majority of human infections. ${ }^{248}$ This implies that the source of the Campylobacter is chicken. Epidemiological studies of Campylobacter patient's risk factors suggest that contact with or consumption of chicken is important as the transmission route of infection. In published studies, the chicken attribution to source of Campylobacter ${ }^{2}$ is higher than the risk factor data representing the transmission route. ${ }^{3}$ This may result from transmission from chicken being indirect and not through the usual eating or handling routes. Chickens can carry multiple strains ${ }^{49}$ and coinfection with more than one isolate occurs in about $8 \%$ of patients. ${ }^{50}$

\section{Disease burden}

The disease burden from Campylobacter has been estimated to be 500000 cases per year with 80000 GP consultations, based on cohort and GP studies conducted over 16 months. ${ }^{1}$ However, there could be substantial underascertainment in areas with greater deprivation and/or a larger ethnic population. It remains unclear why there are more cases in men than in women, and why infection is more common in rural than in urban environments.

\section{Implications}

Research needs to be focused on intervention, which in turn requires a better understanding of the epidemiology. Typing data has been useful for attribution to sources and may also be useful in measuring the impact of interventions targeted at reducing the contamination of chickens. This work suggests that there could be advantages in using the archive of strains that have been typed by serotype and phage type as a resource for examining longer term changes by linking the phenotypic and MLST typing and applying source attribution. There is a need for whole genome MLST typing on a percentage of strains obtained through surveillance over a longer time period. However, there is also a need to better understand the drivers for change other than source (eg, transmission route, climate, impacts of immunity). The work suggests that the underlying population contributes significantly to the disease epidemiology and this is an area where further examination may be productive. The five elements of difference and the factors that are driving these are examined in table 2. It would be attractive to better understand whether the numerous rare types are a reflection of recent emergence as a result of immunological pressure or are just rare, with a longer pedigree. There is also scope for additional work on transmission vectors, such as flies, which seem to play a role in biosecurity problems and may also directly contribute to human disease.

Acknowledgements The authors acknowledge the very large number of clinical, laboratory, scientific and Environmental Health staff who were responsible for diagnosing and reporting cases over the timescale of the review. Thanks are also extended to the people who contributed to sentinel surveillance, case-control and other studies for other data on typing.

Contributors GLN compiled the surveillance data and did the descriptive analysis. JFR compiled the phenotyping data. SKS compiled the genetic typing data. CL linked surveillance data to geographic markers, population density and socioeconomic variables. CS linked the location and date with recent local rainfall and temperature. All contributed to the final manuscript.

Funding There was no funding associated with this work. Work was conducted using the in-kind resources of the contributing organisations only.

\section{Competing interests None.}

Ethics approval Ethics approval was provided by the Surveillance data only.

Provenance and peer review Not commissioned; externally peer reviewed.

Data sharing statement The descriptive data presented in the paper are available for use by others. Numbers for the figures are available as a supplementary file with this paper and on the Dryad website. The evidence base for table 2 is also available.

\section{REFERENCES}

1. Tam CC, Rodrigues LC, Viviani L, et al. Longitudinal study of infectious intestinal disease in the UK (IID2 study): incidence in the community and presenting to general practice. Gut 2012;61:69-77.

2. Sheppard SK, Dallas JF, Strachan NJ, et al. Campylobacter genotyping to determine the source of human infection. Clin Infect Dis 2009;48:1072-8.

3. Tam CC, Higgins CD, Neal KR, et al. Chicken consumption and use of acid-suppressing medications as risk factors for Campylobacter enteritis, England. Emerg Infect Dis 2009;15:1402-8.

4. Mullner $\mathrm{P}$, Shadbolt T, Collins-Emerson JM, et al. Molecular and spatial epidemiology of human campylobacteriosis: source association and genotype-related risk factors. Epidemiol Infect 2010;138:1372-83.

5. Mullner P, Spencer SE, Wilson DJ, et al. Assigning the source of human campylobacteriosis in New Zealand: a comparative genetic and epidemiological approach. Infect Genet Evol 2009;9:1311-19.

6. Louis VR, Gillespie IA, O'Brien SJ, et al. Temperature-driven campylobacter seasonality in England and Wales. Appl Environ Microbiol 2005;71:85-92.

7. Gillespie IA, O'Brien SJ, Bolton FJ. Age patterns of persons with campylobacteriosis, England and Wales, 1990-2007. Emerg Infect Dis 2009;15:2046-8.

8. Doorduyn Y, Van Den Brandhof WE, Van Duynhoven YT, et al. Risk factors for indigenous Campylobacter jejuni and Campylobacter coli infections in The Netherlands: a case-control study. Epidemiol Infect 2010;138:1391-404.

9. Fitzenberger J, Uphoff $\mathrm{H}$, Gawrich $\mathrm{S}$, et al. Urban-rural differences of age- and species-specific campylobacteriosis incidence, Hesse, Germany, July 2005 - June 2006. Euro Surveill 2010;15:19693.

10. Strachan NJ, Gormley FJ, Rotariu O, et al. Attribution of Campylobacter infections in northeast Scotland to specific sources by use of multilocus sequence typing. J Infect Dis 2009; 199:1205-8.

11. Garrett N, Devane ML, Hudson JA, et al. Statistical comparison of Campylobacter jejuni subtypes from human cases and environmental sources. J Appl Microbiol 2007;103:2113-21.

12. Green CG, Krause DO, Wylie JL. Spatial analysis of campylobacter infection in the Canadian province of Manitoba. Int $J$ Health Geogr 2006;5:2.

13. Hearnden $\mathrm{M}$, Skelly $\mathrm{C}$, Eyles $\mathrm{R}$, et al. The regionality of campylobacteriosis seasonality in New Zealand. Int J Environ Health Res 2003;13:337-48.

14. Sibbald CJ, Sharp JC. Campylobacter infection in urban and rural populations in Scotland. J Hyg (Lond) 1985;95:87-93.

15. Gillespie IA, O'Brien SJ, Frost JA, et al. A case-case comparison of Campylobacter coli and Campylobacter jejuni infection: a tool for generating hypotheses. Emerg Infect Dis 2002;8:937-42.

16. Frost JA, Kramer JM, Gillanders SA. Phage typing of Campylobacter jejuni and Campylobacter coli and its use as an adjunct to serotyping. Epidemiol Infect 1999;123:47-55.

17. Frost JA, Oza AN, Thwaites RT, et al. Serotyping scheme for Campylobacter jejuni and Campylobacter coli based on direct agglutination of heat-stable antigens. J Clin Microbiol 1998;36:335-9.

18. Maiden MC, Bygraves JA, Feil E, et al. Multilocus sequence typing: a portable approach to the identification of clones within populations 
of pathogenic microorganisms. Proc Natl Acad Sci U S A 1998;95:3140-5.

19. Tam CC, Rodrigues LC, O'Brien SJ. Guillain-Barre syndrome associated with Campylobacter jejuni infection in England, 20002001. Clin Infect Dis 2003;37:307-10.

20. Tam CC, O'Brien SJ, Petersen I, et al. Guillain-Barre syndrome and preceding infection with campylobacter, influenza and Epstein-Barr virus in the general practice research database. PLoS One 2007;2: e344.

21. Tam CC, Rodrigues LC, Petersen I, et al. Incidence of Guillain-Barre syndrome among patients with Campylobacter infection: a general practice research database study. J Infect Dis 2006;194:95-7.

22. Nichols GL. Fly transmission of campylobacter. Emerg Infect Dis 2005;11:361-4.

23. Garcia Rodriguez LA, Ruigómez A, Panés J, et al. Use of acidsuppressing drugs and the risk of bacterial gastroenteritis. Clin Gastroenterol Hepatol 2007;5:1418-23.

24. Leonard J, Marshall JK, Moayyedi P. Systematic review of the risk of enteric infection in patients taking acid suppression. $A m ~ J$ Gastroenterol 2007;102:2047-56.

25. Larner AJ, Hamilton MI. Review article: infective complications of therapeutic gastric acid inhibition. Aliment Pharmacol Ther 1994;8:579-84.

26. Royal College of General Practitioners. Royal College of General Practitioners Weekly Returns Service Annual Reports, 2008. http:// www.rcgp.org.uk/clinical_and_research/rsc/annual_reports.aspx (accessed 15 Apr 2011).

27. White AN, Kinlin LM, Johnson C, et al. Environmental determinants of campylobacteriosis risk in Philadelphia from 1994 to 2007. Ecohealth 2009;6:200-8.

28. Kovats RS, Edwards SJ, Charron D, et al. Climate variability and campylobacter infection: an international study. Int J Biometeorol 2005;49:207-14.

29. Guerin MT, Martin W, Reiersen J, et al. House-level risk factors associated with the colonization of broiler flocks with Campylobacter spp. in Iceland 2, 2001-2004. BMC Vet Res 2007;3:30.

30. Meldrum RJ, Griffiths JK, Smith RM, et al. The seasonality of human campylobacter infection and Campylobacter isolates from fresh, retail chicken in Wales. Epidemiol Infect 2005;133:49-52.

31. Wilson IG. Salmonella and campylobacter contamination of raw retail chickens from different producers: a six year survey. Epidemiol Infect 2002:129:635-45.

32. Hudson JA, Nicol C, Wright J, et al. Seasonal variation of Campylobacter types from human cases, veterinary cases, raw chicken, milk and water. J Appl Microbiol 1999;87:115-24.

33. Ekdahl K, Normann B, Andersson Y. Could flies explain the elusive epidemiology of campylobacteriosis? BMC Infect Dis 2005;5:11.

34. Jorgensen F, Ellis-Iversen J, Rushton S, et al. Influence of season and geography on campylobacter jejuni and C. coli subtypes in housed broiler flocks reared in great britain. Appl Environ Microbiol 2011;77:3741-8.

35. Bi P, Cameron AS, Zhang $\mathrm{Y}$, et al. Weather and notified Campylobacter infections in temperate and sub-tropical regions of Australia: an ecological study. J Infect 2008;57:317-23.

36. Tam CC, Rodrigues LC, O'Brien SJ, et al. Temperature dependence of reported Campylobacter infection in England, 1989-1999. Epidemiol Infect 2006;134:119-25.

37. Jore $\mathrm{S}$, Viljugrein $\mathrm{H}$, Brun $\mathrm{E}$, et al. Trends in Campylobacter incidence in broilers and humans in six European countries, 1997-2007. Prev Vet Med 2010;93:33-41.

38. Patrick ME, Christiansen LE, Waino M, et al. Effects of climate on incidence of Campylobacter spp. in humans and prevalence in broiler flocks in Denmark. Appl Environ Microbiol 2004;70:7474-80.

39. Hartnack S, Doherr MG, Alter T, et al. Campylobacter monitoring in German broiler flocks: an explorative time series analysis. Zoonoses Public Health 2009:56:117-28.

40. Hald B, Skovgard H, Pedersen K, et al. Influxed insects as vectors for Campylobacter jejuni and Campylobacter coli in Danish broiler houses. Poult Sci 2008;87:1428-34.

41. Hald B, Skovgard H, Bang DD, et al. Flies and Campylobacter infection of broiler flocks. Emerg Infect Dis 2004;10:1490-2.

42. Hald B, Sommer HM, Skovgard H. Use of fly screens to reduce Campylobacter spp. introduction in broiler houses. Emerg Infect Dis 2007;13:1951-3.

43. Guerin MT, Martin SW, Reiersen J, et al; Campy-on-Ice Consortium Temperature-related risk factors associated with the colonization of broiler-chicken flocks with Campylobacter spp. in Iceland, 2001-2004. Prev Vet Med 2008;86:14-29.

44. Nelson W, Harris B. Flies, fingers, fomites, and food. Campylobacteriosis in New Zealand-food-associated rather than food-borne. N Z Med J 2006;119:U2128.

45. Nichols GL. Disease transmission by non-biting hlies. In: Ayres JG, Harrison RM, Nichols GL, et al, eds. Environmental Medicine. London: Hodder Arnold, 2010:434-46.

46. Dingle KE, Colles FM, Ure R, et al. Molecular characterization of Campylobacter jejuni clones: a basis for epidemiologic investigation. Emerg Infect Dis 2002;8:949-55.

47. Dingle KE, Colles FM, Wareing DR, et al. Multilocus sequence typing system for Campylobacter jejuni. J Clin Microbiol 2001;39:14-23.

48. Sheppard SK, Dallas JF, MacRae M, et al. Campylobacter genotypes from food animals, environmental sources and clinical disease in Scotland 2005/6. Int J Food Microbiol 2009;134:96-103.

49. Forbes KJ, Gormley FJ, Dallas JF, et al. Campylobacter immunity and coinfection following a large outbreak in a farming community. $J$ Clin Microbiol 2009;47:111-16.

50. Richardson JF, Frost JA, Kramer JM, et al. Coinfection with Campylobacter species: an epidemiological problem? J Appl Microbiol 2001;91:206-11. 